\title{
ERRATUM
}

Ismene L. Petrakis · Stephanie O'Malley •

Bruce Rounsaville $\cdot$ James Poling •

Colette McHugh-Strong • John H. Krystal • VA

Naltrexone Study Collaboration Group

\section{Naltrexone augmentation of neuroleptic treatment in alcohol abusing patients with schizophrenia}

Published online: 4 June 2004

C) Springer-Verlag 2004

\section{Psychopharmacology (2004) 172:291-297}

In Fig. 1, page 294, the naltrexone data are missing from the graph. The correct figure appears here.

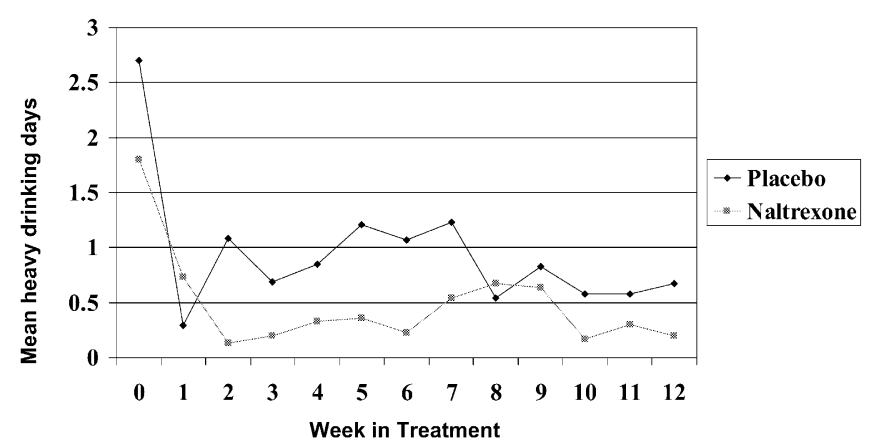

Fig. 1 Mean weekly heavy drinking days ( $\geq 5$ drinks per episode) at baseline and during the active phase for subjects on naltrexone versus placebo

The online version of the original article can be found at http://dx. doi.org/10.1007/s00213-003-1658-9

I. L. Petrakis · S. O’Malley · B. Rounsaville · J. Poling ·

C. McHugh-Strong $\cdot$ J. H. Krystal

Department of Psychiatry, Yale University,

New Haven, Conn., USA

I. L. Petrakis $(\bowtie)$

West Haven Veterans Administration Medical Center \#116-A,

950 Campbell Avenue,

West Haven, CT 06516, USA

e-mail: ismene.petrakis@yale.edu

Tel.: +1-203-9325711 ext 2244

Fax: +1-203-9374791 